\title{
Using drawing in visual research: materializing
}

\author{
the invisible
}

\author{
Philippa Lyon
}

\section{INTRODUCTION:}

\section{CONTEXTS AND THEORETICAL CONSIDERATIONS}

\section{Why drawing?}

Drawing is as fundamental to the energy which makes us human as singing and dancing.

(Berger, 2007: 109)

The idea that Berger alludes to here is that drawing has a peculiarly innate, primitive connection with what makes us human. It is often this tacit belief in the universality and democracy of drawing as an activity that propels researchers to turn to it for insights into human experience, perceptions and behaviour. In an era where visual methods have acquired a new urgency, this chapter explores the possibilities and limitations of drawing as research technique, frequently but not necessarily manual, simple in its technological requirements and extremely intimate in its focus: 
Drawing is an intimate occupation; it is by nature a First Person activity because of the direct connection between the individual and the marks (s)he makes. Its most fundamental characteristic is that it evolves as it progresses it is a process.

(Cain, 2010: 265)

If Berger suggests drawing is a mark of humanity and Cain implies it is individualistic, intimate and process-oriented, others have been more concerned with claims that drawing is a cognitive activity. In his analysis of the way in which visual scholarship needs to be developed, Newbury has argued that it is sometimes forgotten that images have agency, that 'images are not ideas in disguise, but are themselves intellectual propositions' (Newbury, 2011: 652). Drawings, as images, can indeed be seen in these terms but in addition, the very process of drawing can be integral to knowledge discovery and development (McGuirk, 2011). For Petherbridge 'drawing renders thought visible through its simple tools and unimpeded technique, and functions as the most direct externalization of the conceptual' (2010:2).

\section{What is drawing?}

What we might mean and refer to by the verb or noun 'drawing' is a subject of debate in the art world (Duff and Davies, 2005; Garner, 2008; the TRACEY Drawing and Visualisation Journal; Drawing: Research, Theory, Practice journal) with an increasing emphasis on liberal definitions that embrace conceptual as well as material drawing. In the contemporary perspective of many arts educators and practitioners drawing need not be representational, it need not be understood purely as a two dimensional practice, nor as a manual activity. Increasingly, drawing has loosened 
itself from an attachment to any specific medium. Whilst the sketchbook, life drawing class and other traditional drawing practices continue to be found within art schools, underpinning philosophical assumptions about what drawing is and does vary a great deal (Riley, 2008). Drawing can be a digital process or it can be an activity carried out on a vast scale using feet or vehicles as the drawing instrument, moving across tracts of land or water. It might involve constructing marks through a system of rules or by means of a machine. The implications of this diversity have been acknowledged:

.. the danger might be that one is left with a clear impression that drawing can be anything. This has the constituent problem that if drawing is everything, then it is also nothing - or at least nothing special.

(Taylor, 2008: 11)

Petherbridge, who clearly states her belief that drawing is the basis of 'all art and visual thinking' takes a positive perspective on this eclecticism, proposing that drawing be viewed as a 'continuum' which extends from the 'open-ended sketch to the finished work' (2010: 2-3). Indeed many different types of drawing practices thrive in professional settings. Some of these drawing practices have an established, instrumental role, or at least one that is not regularly subjected to epistemological interrogation. Designers, school teachers, cartographers, architects, archaeologists and health professionals, to name a few, all use manual or digital drawing to envision, develop, plan, record, learn, reflect upon and communicate within their professional roles and lives. Artist Tania Kovats has gathered together examples of drawings from within diverse professions, arguing that drawing needs to be understood not simply as a representational tool but as an exploratory mechanism (2014). In determining the 
boundaries around drawing for the purposes of research, some awareness of this breadth and range of practices and the context-dependent nature of drawing is helpful. It is perhaps most important, however, in selecting the terminology, materials and approaches to drawing for research purposes, to be conscious of the social and cultural norms and values relevant to your project and participant group. In this chapter, which considers how drawing might be used to address a range of research topics and contexts, I will begin with a practical and generic 'base line' definition of drawing as intentional mark-making on a receptive surface. I hope, though, that researchers will argue with and amend this according to the specific needs and conditions of their own research.

\section{A brief note on 'types' or classifications of drawing}

There are a number of descriptive terms applied to drawing, among the most common of which are 'sketch', 'objective drawing' and 'subjective drawing'. A 'sketch' tends to be understood as having a quality of being provisional or unfinished. It has become associated with the idea that it will generate further thought or ideas and is also seen as being able to 'capture nuances of the observed world' (Petherbridge, 2010: 3).

'Objective drawing' privileges the rational and logical. This might mean focusing on the mimetic quality of the image, particularly through the use of empirical, measurement-based techniques, where the subject is usually visible and tangible. The motivations for such drawing might, for example, be to record, investigate or interrogate. The term objective drawing is also sometimes used to refer to diagrammatic or schematic drawing designed to clarify and convey concepts. 'Subjective drawing' is seen as primarily expressive, whether as a means of dialogue with the self (Bakhtin, 1981) or as a form of communication with others. For and 
Betti, objective drawing 'conveys information, not feelings', and subjective drawings are 'expressive and intuitive' (2011: 10). There are, though, variations in how these terms are used and other ways of categorizing or describing drawing practices, depending on the sources you consult. In Writing on Drawing: Essays on Drawing Practice and Research, edited by Steve Garner, as one example, contributors discuss a range of terms from 'speculative' or 'investigative' drawings relating to sculptural practice (Talbot, 2008: 43) through to 'ideational drawing', referring to the use of drawing as 'thinking space' in design education (Rosenberg, 2008). In the research methods context, though, depending on the nature of the research question and participant group, the question at the outset might rather be whether it is necessary or desirable to deploy such terms or focus on drawing knowledge or skill. A number of research studies make it clear that it is not, such as the project that explored how energy is visualized through drawing: 'It was important to note that this was not a study of people's drawing skills or observational drawing proficiency' (Bowden et al, 2015: 23). A clear and accessible explanation of how the participants might best understand and approach their drawing activity is likely to be more helpful at the outset. Ways of categorizing drawing become more significant in the approach to the analysis of data, where the researcher (possibly in conjunction with their participants) needs to adopt or develop a framework through which they can organize and interpret the drawing processes and the drawings that have been produced. At this point, however, analytical categories need to be rationalized in terms of the goals and values of the study itself and not purely adopted or transposed from an art historical or art educational context. 


\section{Cultural contexts to drawing}

There are many competing schools of thought about the development of children's drawing (Anning, 2008; Anning and Ring, 2004; Harrison, Clarke and Ungerer, 2007). Whereas once the earliest 'scribble' drawings were viewed as transitional, a sign of the motor activity of the body, more recent research claims that such marks contain intent, including intent to communicate (Longobardi, Quallia and O.lotti, 2015). Drawing has been used as visual research method suitable for eliciting a range of data from children, in the context of psychological theories that children's drawings can be viewed as measure of 'internal representations' (Jolley, 2010: 153179). Further, a request to a child to draw their experiences or perceptions is sometimes seen as a strategy that engages them in their own terms and thus as a participatory, as opposed to 'top-down' approach. Such research studies tend to combine the drawing with writing or talk and sometimes both (Angell, Alexander and Hunt, 2014). In her practice as an educational psychologist, Linda Theron describes drawings as a 'wonderful tool':

With shy children drawings often broke the ice. With boisterous youngsters, drawings regularly stilled them and encouraged them to reflect .. When my clients were troubled by something that seemed very overwhelming, it helped to concretise the issue as a drawing.

(Theron, 2011:4)

Where research aims to focus on experiences or views that might be intellectually difficult for a child to articulate or emotionally upsetting to recall and describe, drawing is sometimes thus mooted as helpful both in creating a focus and point of 
constructive contact between researcher and participant, and in offering a means of representation that does not rely entirely on the verbal mode. It has been argued that these assumptions are themselves shaped by an adult ('top-down') perspective and there have been concerns about the limitations of focussing predominately on the drawings made, and not on the social circumstances of the research or the process of the drawing itself (Backett-Milburn and McKie, 1999). However this type of approach, generally referred to as 'draw-and-write' or 'draw-write-and-speak', has been probably one of the most commonly used drawing-based research approaches and is still adopted as a means of eliciting reflections, perceptions, views and experiences with children.

There has traditionally been far less inclination for researchers to use drawing with adults. Whereas children tend to draw freely in infancy, the level and nature of the child's engagement with drawing appears to change at around 7 or 8 years old. This has been theorised as being due to children being socialized into a world in which the verbal is dominant, and to the lack of drawing instruction children receive at a stage when they see the ability to represent accurately as very important (Goodman, 1976). Others have cited the influence of different cultural values surrounding children's drawing as possibly more significant (Davis, 1997). The decrease in drawing confidence and fluency seems to be associated with a decline in the use of drawing as a medium of learning. Adults' perceptions of what drawing involves, their assumptions about its cultural standing and their willingness to engage with it varies a great deal: these factors may account at least in part for why researchers have been less inclined to turn to drawing in studies with adult participants. The socio-cultural environment for adult drawing may require them to negotiate stereotypes of 'good' 
and 'bad' drawing, of 'artiness' and of drawing that might be seen as 'childlike' or 'childish'. Yet as this chapter will go on to explore, such concerns can often be easily overcome. Drawing can offer very effective routes to the expression, articulation and analysis of thoughts, opinions, experiences, perceptions and behaviour of adult participants and can also be greeted 'with pleasure' (Bowden et al, 2015).

\section{METHODS}

\section{A. Overview of drawing in research}

Mirzoeff has commented that our 'disjunctured and fragmented' contemporary culture is 'best imagined and understood visually' (1999: 5). This implies not only the need for investigation into the arguments offered by found, pre-existing visual material but also for deep engagement with creative visual practices within the research process. In turning our attention to the potential role of drawing within research, then, we will engage most directly with the body of work on the 'researcher-instigated' creative, visual methods (Pauwels, 2011). Drawing is sometimes situated as part of the move towards participatory and accessible modes of research (Knowles and Cole, 2008: 2) although this needs to be considered with some caution and judgement. It is not selfevident that the use of drawing is fused to a 'participatory' ethos and methodology in research: this might not be the aim of all drawing methods studies. Sapochnik explores 'the production of drawings by the observer/researcher as a mean to access tacit knowledge and unconscious perceptions ' (2013: abstract) and uses drawing to 'allow access to more elusive sources of meaning' (2013: 7). In the sections that follow it is possible to see how researchers deploy drawing as a means to create a material trace or indicator of a more typically immaterial or inaccessible phenomenon: whether this is of a cognitive process, the generation of a creative idea, 
the visualization of an intangible concept or perception, or the development of an insight. For some, drawing is seen as an expressive act for the individual researcher or research participant who is drawing, while also producing visual material that is evocative, communicative and above all, has a haptic presence. As Mitchell puts it:

What I like about drawings is their tangibility, their concreteness. We can lay out 50 or 100 drawings and look at them and touch them. [...] I like the immediacy of drawings and their potential to move audiences.

(Mitchell et al, 2011: 2)

Yet if the drawing process or finished drawings can give the impression of an appealing and affective simplicity and directness, the analysis has to raise complex questions. Faced with data consisting of observations of the drawing process and a collection of 'completed' drawings, analytical frameworks need to be applied. Gillian Rose has commented that 'interpreting images is just that: interpretation', yet she places emphasis on the need for interpretation to be a considered process, and on there being a range of equally acceptable approaches to interpreting images (Rose 2012).

The sections below set out approaches that focus to quite different extents on the process and products of drawing. For some projects the process has greater emphasis than the drawings that result. Here, there is often an explicit assertion of the value of taking sufficient time to draw, allowing phases of thought, reflection and drawing concentration to unfold. In parallel are the questions of whether, how and when there should be a verbal elucidation of the process of drawing and how best the multimodal nature of such a process can be captured. Others focus far more on the 
drawings themselves as comprising the key 'data'. Yet in the latter case, too, careful attention is still paid to the conditions of drawing. There is increasingly an understanding that drawing needs to be accountable within research as an activity with a complex set of interconnections to the participant's (and researcher's) social and cultural worlds. Researchers need to be conscious and self-reflexive about the impact they have on those they invite to draw, and acknowledge this as an integral part of their research design (Watts, 2009; Hollway and Jefferson, 2000).

\section{A.1 Using drawing to investigate concepts and experiences}

One of the ways in which drawing can be used is as an elicitation tool capable, for example, of gathering a large quantity of data to explore participants' understandings of a particular concept. As mentioned in the introduction, the 'draw-and-write' or 'draw-write-and-speak' technique has been used with child participants, particularly in the field of educational research, and to a lesser extent with adults. The iSquare team of researchers has adapted this technique for their research with adults, describing it as a 'novel application of the draw-and-write technique' (Hartel et al, 2017: 1). The iSquare research program derived from a key problem within information science, which is the contested nature of the definition of information. Setting out to explore, among other questions, how people visualize the concept of information, the team developed a precise and extensively-tested protocol. Participants are usually drawn from pre-existing groups or audiences, such as students in a classroom or conference delegates. They are given squares of white paper of a standard size and black drawing pens and asked to produce a drawing in response a question within the seven minute time slot. This is designed to 'gently guide the participant to a succinct (not sprawling) visual expression' that suits a quick drawing 
activity' (Hartel et al, 2017: 9). Finally, participants are asked to write a few words about their drawing on the back of the paper square. At the end of this data-gathering phase, an array of participant-produced 'isquare' cards has been accumulated (see Figure 1). The researchers then engage with these data through a range of analytical frameworks: methods used by the iSquare team include compositional interpretation, thematic analysis, content analysis and pictorial metaphor analysis (Hartel et al, 2017: 5). It is worth noting that in more recent work, however, the team has begun to identify and test more participatory methods for the analysis of the data sets. This involves a sequence of five stages of analysis and within this, 20 separate activities, in which one researcher, using a prepared text, verbally prompts participants to engage in a number of observational and analytical exercises, intermittently inviting open discussion. This interactive mode of drawing analysis offers, it is argued, a range of benefits including: a greater degree of participant intimacy with the images, a range of different analytical perspectives and the enabling of other relevant meanings to be identified and concerned beyond the formal concept being investigated.

One of the intriguing features of this approach is that its empirical and highly systematized nature is combined with a commitment to the importance of visual imagination and attention to the significance of materials, tactility and scale:

The iSquare Protocol embraces materiality through its use of traditional paper and pen. These somewhat old-fashioned technologies inspire beautiful and compelling drawings, perhaps because they return participants to the drawing practices from their youth. .. The textured surface of quality drawing paper is 
porous and best for absorbing black ink quickly without smudging. The paper should be heavy enough that markings do not bleed to the other side... (Hartel et al, 2017: 9)

This 'embracing of materiality' is also evident in the way the team uses drawing data for exhibitions, both as a means to disseminate research findings and as a basis to offer informal invitations for further contributions. The researchers encourage close physical proximity in their audiences to encourage a process of peering at, and handling, the drawing data.

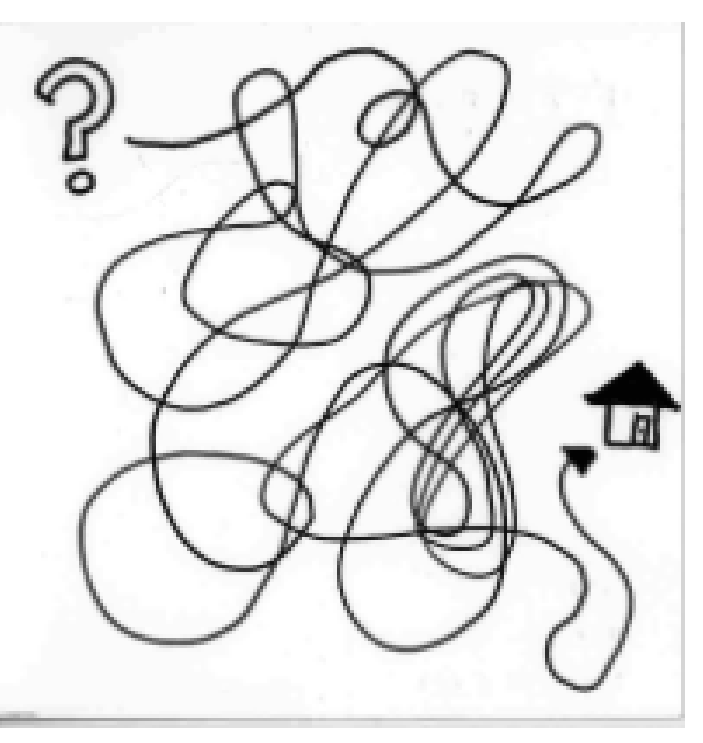

Figure 1. Participant drawn visualization of the concept of information.

\section{(Hartel et al, www.iSquares.info)}

In another example, researchers set out to use drawing to explore the question 'what does energy look like', to 'uncover the associations people make with this immaterial entity' (Bowden et al, 2015: 19). In this case the approach taken was explicitly participatory, with drawing taking place through workshops that encouraged a degree 
of material experimentation. No verbalisations (writing, speaking or questionnaires) were requested as part of the research process, thus the analysis resulted purely from the researchers' interpretations of the images produced.

\section{A.2 Using drawing for in-depth inquiry into individual perceptions and experiences}

In the studies above, drawing was used primarily to gather, survey and analyse a quantity of drawn visualisations in order to gain deeper insight into a particular concept, although this could apply to other research subjects. In this section drawing is also used as a method of elicitation but its purpose is to inquire into a participant's world, or a particular aspect of it, in depth; usually with a focus on particular views, experiences or perceptions. For this reason it can align usefully (but not exclusively) with phenomenological approaches. These drawing methods tend to include spoken dialogue or writing as an adjunct to the drawing process. They also tend to involve speaking or writing activities to elucidate the finished drawings, which is rationalized as helping to ensure that the participant's meaning is at the centre of the analysis (Mannay, 2016; Rose, 2011). In some cases there might be an advance briefing to help build rapport between researcher and participant, as well as post-drawing explanation, reflection and review. These projects vary in the encouragement given to participants to experiment with the scale of their drawing or the materials they use. They also vary in the degree of distance maintained between the researcher and participant and in whether participants are provided with instructions by the researcher, or involved in setting the terms of the drawing exercise in a more participatory style. In some cases drawing occurs in a group setting. Individual participants might create drawings with reference to their own experience and 
thoughts but then subsequently share and discuss their meaning within their participant group ${ }^{1}$.

The Manual Clinical Drawing research project (Lyon and Turland, 2016) is an example of using drawing, as part of an interview method, to investigate particular perceptions and experiences. This study focused on drawing practices routinely found within healthcare exchanges: doctors, nurses and others health professionals make manual drawings, diagrams or sketches when they are reassuring and providing explanations to patients. Additionally a professional might draw a diagram and leave it in patient notes to inform a colleague of a diagnosis or nursing care needs. In the study, the researchers aimed to explore the in-depth perceptions and experiences of a small number of health professionals who drew for their patients and colleagues. The primary method used was the formal, semi-structured research interview, with the addition that each participant was invited to produce examples of the type of drawing they were discussing as part of the interview exchange (see Figure 2). They were informed at the point of recruitment that they would be invited but not obliged to draw as part of the interview.

Here, the assumptions and perceptions surrounding drawing came strongly into play. The fact that the participants made regular drawings as part of their working life did not correlate with confidence about drawing ability and several participants prefaced their drawing activity with protestations of their lack of artistic ability and the

\footnotetext{
1 In Scott's PhD research, a participant group comprising older people and health professional students took part in a 'drawing programme' to explore perceptions of 'self-ageing'. The drawing exercises were planned, staged and combined with discussion over the four weeks of the research, as a thinking space, to enable gradual, phased exploration and reflection. In this research drawing was used as a fused drawing-phemonmenography methodology, a rationalised system of methods, rather than purely as a technique.
} 
likelihood of their producing a 'bad drawing'. Yet once these anxieties were dispensed with all participants commenced drawing, with several drawings made in each interview. Participants were offered pieces of plain, loose-leaf paper and a selection of pencils and pens, chosen for their utilitarian appearance. As 'artistic' or 'fine art' drawing was not the issue at stake, and potentially amplified concerns about the cultural expectations around drawing, materials needed to be as generic as possible. Drawings tended to take between 10 seconds and a minute to produce. The act of making a drawing was usually accompanied by a participant's explanatory narration, or by the continued dialogue between researchers and participant, and occasionally there were short silences whilst participants drew. This method was conceptualised as conscious re-enactment of everyday clinical drawing practices, with the goal of understanding the participant's world view and perceptions of their drawing habits as deeply as possible. In this case the method and referent of the research overlapped: the research findings indicated that the health professionals interviewed viewed drawing as particularly effective in communicating, recording and reassuring, and were thus (despite brief qualms) able to replicate this within the research process.
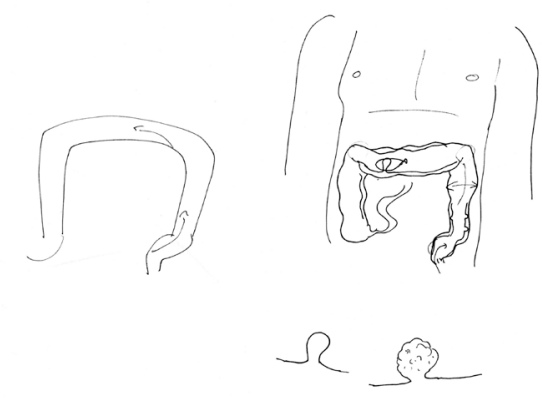

Figure 2. Participant drawing of endoscopy procedure by Daniel Hansen.

Manual Clinical Drawing study (Lyon and Turland). 
In the Manual Clinical Drawing project a key focus was on the way in which participants drew, and talked whilst they drew, in the research interview. This not only produced data on how drawing was perceived by health professionals in clinical contexts but also provided an opportunity for the researchers to consider the impact of the images being produced on the communication exchange, including elements such as the sequence, speed and weight of drawing marks being made. Whilst the completed drawings were retained as data they were less meaningful as objects isolated from the context of their production. They were thus analysed carefully in relation to the relevant section of the transcript. Noting Backett-Milburn and McKie's critique of draw-and-write methods that pay insufficient attention to the social construction of drawings (1999), this approach attempted to refocus the research gaze onto the construction of the interview itself, to consider how the making of such drawings interrelated with annotations and spoken narratives. In this research, as elsewhere (Lyon et al, 2012), the focus of the research was the participants' experiences of drawing within their professional practice, resulting in a coalescing of topic and method.

Further examples of how drawing can be used to explore perceptions and experiences within research are encapsulated within Picturing Research: Drawing as a Visual Methodology (Theron et al, 2011). This is a book of methodological considerations and case studies in the fields of education and educational psychology, all of which are concerned with drawing as a research method ${ }^{2}$. Underpinning this is a stance towards involving communities and participants themselves deeply within the

\footnotetext{
2 This includes a chapter 'Drawing as Research Method', Mitchell et al, 2011: 19-36.
} 
research. The projects were carried out mainly in Southern African countries and a fundamental claim made by the authors is that drawing can 'give voice to the traditionally voiceless, encourage expression, and demand attention' (Mitchell et al, 2011: 26). For Theron, drawings 'are an accessible data generation process as long as they are embedded in an ethical, participant-researcher collaboration' (Mitchell et al, 2011: 5) and as such were appropriate within research as social change.

In Picturing Research, the contributing chapters narrate a range of research subjects and distinct and nuanced ways in which drawing was used within each project, with an underlying focus on using drawing to make deep, person-centred inquiries into issues and experiences that are hard to verbalise. Mitchell et al emphasise this point by referring to Weber's argument that: 'artistic images can help us access those elusive hard-to-put-into-words aspects of knowledge that might otherwise remain hidden or ignored' (Weber, 2008: 44). The focus is on inquiring into participant worlds through drawing, and in concert with this, harnessing the power of participantelicited drawings to provoke thought and evoke strong reactions. In a Rwandan project designed to develop policy on violence against women and children, a participant had created a drawing of a woman throwing a baby down a toilet following an unwanted pregnancy. When projected to a room of policy-makers in large format as part of a research presentation, the audience found it difficult to look away. For Mitchell this reaction is significant, commenting that 'the image "haunts" as Susan Sontag (2003) would have said." (Mitchell, 2011: 2) 


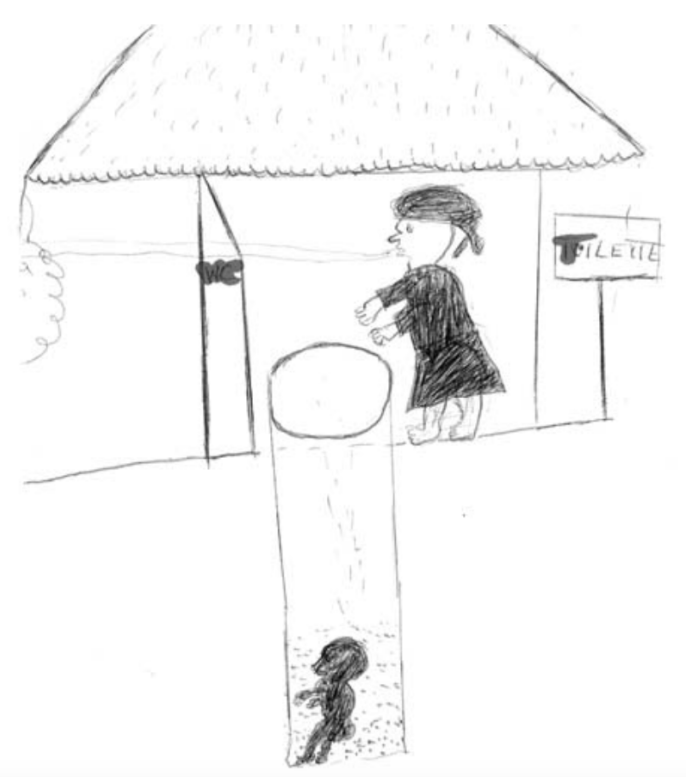

Figure 3. Participant drawing 'Baby' (Theron et al, 2011: 3)

\section{A.3 Using drawing as a dialogic method between participant and researcher}

In this section, 'dialogic' methods are those where drawing is the primary research activity, generated interactively and deliberately as communication, rather than, as in section A2, an invitation within a semi-structured interview. Dialogic methods might best suit the researcher who is interested in intersubjective constructions of meaning between the researcher and participant. Here the drawing marks function almost as a call and response within the partners in the drawing activity, which is either carried out entirely without speaking, or supplemented by verbal questioning and written annotations. In this approach the researcher instigates the drawing but it proceeds in the form of an intentional interpersonal event. The analytical focus is primarily on the process of drawing itself, either constructed bilaterally between researcher and participant, or possibly within a group setting, although the outcomes, the drawings themselves, can also be analysed. The referents of these methods are potentially wide. 
Angela Rogers, in her PhD Drawing Encounters (2008), set out her interest in how best to gain insight into natural human interaction, a longstanding preoccupation of the ethnographic tradition. In Rogers' project, drawing was used as a novel means for facilitating and interrogating one-to-one interactions between adults, via a set of dialogic drawing strategies that could be applied to encounters with strangers met mainly in public settings, such as on trains, exhibitions or in an art college. A key focus of Rogers' work was the problem in research, or more specifically within the post-structuralist tradition in research, of dealing with what Kester has called the 'actuality of human social exchange' (Kester, 2003). How could the research community identify and shape a method able to follow the path or take the shape that casual human conversation takes? The dialogic drawing approach developed by Rogers in her project was designed to address the interpersonal nature and qualities of exchange characteristic of naturalistic casual conversation. With reference to a range of theories on encounter and dialogue (including Buber, 1970; Bohm, 2004; Isaacs, 1999) she explored the idea that in aiming to share human experience, attention needed to be paid to both habitual thinking and bodily experience.

Taking an opportunistic approach to sampling, Rogers was clear that her methods needed to be flexible enough to suit a range of situations and the unpredictable nature of human behaviour. Equipped with a set of basic drawing materials, Rogers would approach potential participants and ask if they would like to draw with her, in the manner of a conversation. In most cases there would be a series of exchanges where the individual approached protested their lack of artistic and/or drawing ability, a research problematic that will be referenced throughout this chapter. Following the initial wariness, however, participants generally became very absorbed: the researcher 
began making the first mark, inviting her participant to respond, and would then reciprocate. For Rogers the relevant analogy here was the non-goal oriented, informal and often humorous experience of 'chatting'. Despite the apparently trivial surface value of such encounters, they can be understood, she argues, as 'the means by which we continually establish who we are, how we relate to others and what we think the world is' (Rogers, 2008, 52). Indeed participants in the project indicated, Rogers writes, 'that the empty white page can act as an analogy of the territory between individuals within which the drawn gestures and responses may embody and reveal participants' feelings, their need for control, their capacity for sharing and their attitude to engaging with the unknown'. (Rogers, 2008: 28).

In concert with this dialogic approach, Rogers developed a practice of reflective drawing that has resonances with the final methods section in this chapter: researcherbased drawing. For Rogers, this drawing was a means of 'thinking, collating, managing, analysing and synthesising and planning the next stage of research'; it was as a method of supporting her creative motivation and enabling critical dialogue with herself and others (Rogers, 2008: 26). It is worth noting here that in the arts, art practice itself can be the medium of reflexivity, as it is for Rogers; in the social sciences this is perhaps more usually done by means of a verbal account, although many variants are available. The researcher Claudia Mitchell encapsulates the spirit of this self-reflexive approach to drawing when she describes how she and her fellow drawing researchers felt it was 'to 'draw ourselves' into the research.' (Mitchell et al, 2011: 1). Rogers' approach is clearly strongly connected to the use of drawing for individual inquiry discussed in section 4.2. It is differentiated by the degree of its commitment to interactive, interpersonal exchange between researcher and 
participant, and characterized by the opportunistic approach to sampling and selection and the conversational nature of the resulting drawing exchanges.

\section{A.4 Researcher-based drawing}

This last section touches briefly on methods and approaches in which drawing is designed and enacted primarily by the researcher, as a tool of investigation and selfreflexivity (see also the references above to the use of drawing for researcher reflection in Rogers and Theron et al). These methods are used by researchers from a wide spectrum of disciplines and contexts: their potential extends well beyond what might be thought to be 'arts' questions. Lesley McFadyen's research into archaeological drawing points to the extent to which drawing is already the focus and method of inquiry in a range of disciplinary contexts (2011). Noting that the perception of archeological drawing as a record was insufficient, McFadyen set out to discover how the compulsion to 'draw the lines' in archeology operates 'in descriptive practice' (2011: 33). What she is keen to emphasise about drawing 'is how it changes the ways we can both write about time and relate prehistoric things to past and future.' (McFadyen, 2011: 33) In order to pursue her inquiry she considered the properties of completed archeological drawings, assessed what she had learned through the process of making the drawings and explored how the knowledge was made explicit. Referring to Tim Ingold's arguments for positioning drawing at the heart of anthropological practice, she argues that archeological drawing is improvisatory, generative and creative; capable of recognizing those elements that are not yet resolved. Such drawing, she writes, 'is itself a form of thinking' (McFadyen, 2011: 42). 
In the second example, Patricia Cain's PhD investigated the extent to which she could understand her own creative process of drawing as an artist. How can an artistresearcher develop a deep and systematic understanding of her own drawing processes? How could she investigate these questions as a practitioner, by 'thinking within the medium?' (Cain, 2011: 31) For Cain this meant dwelling carefully on the 'manner of investigation' embodied by both her research process and her drawing practice. Drawing has a 'processual quality', she argues, which makes it:

'both a method and a methodology; it is a method in the sense that it is a tool for investigation, and a methodology because the inherent nature of the activity determines how as a tool, it can be deployed and interpreted.' (Cain, 2010: 265)

Using Varela et al's theory of enactive cognition, where perception is always a lived experience in which the body is central, Cain carried out a series of investigations based in the embodied experience of drawing, by a painstaking and conscious process of copying specific works (Varela et al, 1991). She comments that: 'drawing as a First Person methodology is an open-ended process of discovery through which it is possible to present what is dynamic in concepts, and from which generalisations can be made from the specificity of what is done.' (Cain, 2010: 266). Here, then, drawing is an experiential as well as a visual methodology and one that can be used by and applied to one's own perceptual experience as a researcher as much as to other 'participants' in research. 


\section{GUIDELINES AND SUMMARY}

This section synthesizes key issues that might help researchers decide whether and how to use drawing methods in their research, particularly for the first time.

\section{Researcher skill and expertise}

If you are aiming to use drawing in a research study, what type of skills and expertise might you need? If it is not, as discussed above, expected that participants have drawing 'skill', it is equally not necessarily a requirement for researchers. In using drawing as a methodology or method it is, however, advisable to have some basic familiarity with key terms and categories in circulation and a theorized understanding of why drawing will be meaningful in your study. It is also advisable to have tried out any processes of drawing that you plan to ask participants to engage in so that you have an experiential base from which to explain activities. It is important to identify a clear layperson's description of what you mean by drawing, and the process of doing this should help you reflect on your own beliefs, assumptions and expectations about drawing. You may also want to consider: is it possible, or desirable, to guide your participants' drawing, or does the approach you are taking require that participants have maximum latitude in responding to the research subject with their mark-making?

\section{Participants and participation in drawing research methods}

As discussed in this chapter, there can be initial anxiety in response to the invitation to draw for research, even after the process of recruiting participants specifically for this purpose. There are a number of ways of judging the appropriateness of the request to draw and of managing this if you decide to go ahead. You might, for example, invite discussion and suggestion about how drawings could be made, or 
offer drawing as one of a range of creative methods, to ensure that participants have some autonomy. This may result in those with more experience, skill or confidence choosing to draw, which needs to be weighed up in the process of analysis. You should always explain when recruiting participants how you are approaching and using drawing, for example, to explore and express views about a particular question/topic. It is important to state whether or not any drawing knowledge or skill is required. The attention paid to conveying the subject of the research is important, to avoid participants becoming too distracted by the idea that a particular quality or artistic style of drawing is expected.

\section{Drawing technologies, materials and time}

The choice of drawing technologies and materials needs to be made through consideration of the research question and the groups from which you intend to recruit. Few studies have yet been identified that have used digital drawing technologies such as touch-sensitive drawing screens, but if resources are available for this medium, it is possible that some participant groups would welcome this. In choosing drawing technologies it is also important to consider the possible connotations they might hold for participants: artist quality sketchpads may be greeted with pleasure by some but seen as symbolic demands for artistic skill by others. Such materials are never completely 'neutral'.

\section{Ethics}

The researcher who aims to elicit drawing from participants needs to be clear at the outset how every aspect of drawing will be treated. Issues of confidentiality, anonymity and data storage and management are as important with the process of 
drawing as with any other form of meaning-making through images. It might be useful to note that whilst participants may be wary or resistant to the associations of drawing with 'art' at the beginning of a research process, the commitment and intimacy required of them may alter their view towards the drawings produced. At the end of long research processes, participants may come to see personal and artistic value in their drawings. It may be productive to adopt a continuous consent approach, in which participants regularly reflect on issues such as who drawings belong to, who keeps analogue and digital versions of drawings and how and to whom drawings might be shown (as research data; as artworks in an exhibition; both?). In addition to offering the standard ethics escape clause for participants to change their mind about the use of the 'data' they have provided, this gives opportunities for participants to dwell or reflect on the project, their drawing experience and how this has affected them.

\section{Analysis}

One of the perceived issues or limitations in using drawing as a research method is the questions of how to analyse the resultant data. How do we know if our interpretation is valid, or whether we have 'over-read' or over-interpreted drawings? How do we know whether we have placed too much significance on, or even clumsily misunderstood what a participant was intending? Depending on the theoretical and methodological underpinnings to your research and the way in which you have defined drawing, you may wish to discuss the relationship between mark-making in action, the finished drawings and any speech and writing about the process and drawings. Even if you are clear that you will focus primarily on drawings as outputs, you will need to take into account impressions of participant behaviour whilst 
drawing, your own influence as the researcher and the circumstances in which drawings are made. For Mitchell (2011), one way to approach the overwhelming multivalence of potential interpretations of a drawing is to put together a group of participants to engage in interpretive discussion collectively.

\section{CONCLUSION}

Drawing has many potential applications in research and is increasingly being experimented with and included in the researcher's toolkit. It is an activity that can be adopted and shaped as a method to suit the needs of distinct research paradigms but can also be a starting point for the researcher, a core inspiration or influence in the development and shaping of methodology. Whilst its traditional cultural associations have implied that drawing is most appropriate with children, there are now multiple examples and considerable interest in how drawing can help open up new territory and facilitate the production of new insights with a wide range of participant groups. The next stages of development for drawing as a research method lie, perhaps, in researchers' adeptness: how can we make optimal use of the appealing lowtechnology, direct, bodily simplicity of drawing as an activity, whilst stewarding drawer-participants carefully through the depth of thoughts and feelings, and visual traces, that result? 


\section{REFERENCES}

Angell, Catherine, Alexander, Jo and Hunt, Jane A. (2014) ' 'Draw, write and tell': A literature review and methodological development on the 'draw and write' research method', Journal of Early Childhood Research, 13, 1: 17 - 28.

Online: https://doi.org/10.1177/1476718X14538592 [accessed 3 Jan 2018).

Anning, Angela (2008) 'Reappraising young children's mark-making and drawing' in

S.Garner (ed.), Writing on Drawing: Essays on Drawing Practice and Research. Bristol and Chicago, IL: Intellect.

Anning, Angela and Ring, Kathy (2004) Making Sense of Children's Drawings. Berkshire: Open University Press and McGraw Hill Education.

Backett-Milburn, Kathryn and McKie, Linda (1999) A critical appraisal of the draw and write technique, Health Education Research, 14, 3: 387-398, https://doi.org/10.1093/her/14.3.387.

Bahktin, Mikhail M. (1981) The Dialogic Imagination. Austin: University of Texas Press. Berger, John and Savage, Jim, (ed.), (2007) Berger On drawing. $2^{\text {nd }}$ edition, Occasional Press.

Bohm, D. (2004) On Dialogue, London: Routledge.

Bowden, Flora, Lockton, Dan, Gheerawo, Rama (ed.), and Brass, Clare (2015) Drawing Energy: Exploring perceptions of the invisible. London: Royal College of Art.

Buber, Martin (1970) I and Thou. Translated from the German by W. Kaufmann. Edinburgh, T. \& T. Clark.

Cain, Patricia (2011) Evolution of the Practitioner. Bristol and Chicago: Intellect.

Davis, J. (1997) 'The what and the whether of the U: cultural implications of understanding development in graphic symbolization', Human Development, 40: 145-154.

Davis, Jo and Duff, Leo (2005) Drawing - The Process. Bristol and Portland, Oregon: Intellect Books.

Drawing: Research, Theory, Practice, Intellect Journals. 
Elkins, James (ed.), (2008) Visual Literacy, New York and Abingdon: Routledge.

Garner, Steve (ed.), (2008) Writing on Drawing: Essays on Drawing Practice and Research.

Bristol and Chicago, IL: Intellect.

Goodman, Nelson (1976) The Languages of Art, Indianapolis, Hackett.

Harrison, Linda, Clarke, Leanne and Ungerer, Judy (2007) 'Children's drawings provide a new perspective on teacher-child relationship quality and school adjustment', Early

Childhood Research Quarterly, 22: 55-71.

Hollway, Wendy and Jefferson, Tony (2000) Doing Qualitative Research Differently.

London: Sage.

Ingold, Tim (ed.), (2011) Redrawing Anthropology: Materials, Movements, Lines. Farnham, England and Burlington, USA: Ashgate.

Isaacs, W. (1999) Dialogue and the art of thinking together: a pioneering approach to communicating in business and in life. New York: Currency.

Jolley, Richard P. (2010) Children and Pictures: Drawing and Understanding. Singapore: John Wiley \& Sons.

Kester, Grant (2003) Position paper [Internet], Pittsburgh, Monongahela Conference on Post Industrial Community Development, Art, Ecology, and Planning with People: Influencing public places we care about. Available at: < http://moncon.greenmuseum.org/ >.

Knowles J. Gary and Ardra L. Cole (2008) Handbook of the Arts in Qualitative Research: Perspectives, Methodologies, Examples and Issues. London: Sage, pp. 41-54.

Kovats, Tania (2014) Drawing Water. Edinburgh: The Fruitmarket Gallery Books.

Longobardi, Claudio, Rocco Quaglia, and Nathalie O. Iotti. (2015) 'Reconsidering the Scribbling Stage of Drawing: A New Perspective on Toddlers' Representational Processes', Frontiers in Psychology, 6: 1227.

Lyon, Philippa and Turland, Martha (2016) 'Manual drawing in clinical communication: understanding the role of clinical mark-making', Visual Methodologies Journal, 5: 1, 39-44. Lyon, Philippa, Letschka, Patrick and Ainsworth, Tom (2012) Drawing in craft and surgery: a conversation, video available online: https://vimeo.com/77975872. 
Mannay, Dawn (2016) Visual, Narrative and Creative Research Methods: Application, Reflection and Ethics. Abingdon: Routledge.

Margolis, Eric and Pauwels, Luc (eds.), (2011) The Sage Handbook of Visual Research Methods. London, California, New Delhi, Singapore: Sage Publications Ltd.

McFadyen, Lesley, (2011) 'Practice Drawing Writing Object' in T. Ingold (ed.), Redrawing Anthropology: Materials, Movements, Lines. Farnham, England and Burlington, USA: Ashgate.

McGuirk, Tom (2011) 'Drawing and intellectualism: contested paradigms of knowledge', Art, Design \& Communication in Higher Education, 10: 2, 217-231.

Mirzoeff, Nicholas (1999) An Introduction to Visual Culture, London, New York:

Routledge.

Mitchell, Claudia, Theron, Linda, Smith, Ann and Stuart, Jean (2011) 'Picturing research: an introduction' in L. Theron, C. Mitchell, A. Smith, and J. Stuart, (eds.), Picturing Research: Drawing as Visual Methodology. Rotterdam, Boston and Taipei: Sense Publishers.

Mitchell, Claudia, Theron, Linda, Stuart, Jean, Smith, Ann and Campbell, Zachariah (2011)

'Drawings as research method' in L. Theron, C. Mitchell, A. Smith, and J. Stuart, (eds)

Picturing Research: Drawing as Visual Methodology. Rotterdam, Boston and Taipei: Sense Publishers.

Newbury, Darren (2011) 'Making arguments with images: visual scholarship and academic publishing' in E. Margolis and L. Pauwels (eds.), The Sage Handbook of Visual Research Methods. London, California, New Delhi, Singapore: Sage Publications Ltd. pp. 651-664. Petherbridge, Deanna (2010) The Primacy of Drawing. New Haven and London: Yale University Press.

Riley, Howard (2008) 'Drawing: towards an intelligence of seeing' in S. Garner (ed.), Writing on Drawing: Essays on Drawing Practice and Research. Bristol and Chicago, IL: Intellect. 
Rogers, Angela (2008) Drawing Encounters: A practice-led investigation into collaborative drawing as a means of revealing tacit elements of one-to-one social encounter. $\mathrm{PhD}$ thesis, University of the Arts London. Online: http://ualresearchonline.arts.ac.uk/4926/

Rose, Gillian (2011) Visual methodologies: An Introduction to interpreting visual materials. $3^{\text {rd }}$ ed. London: Sage.

Rosenberg, Terry (2008) 'New beginnings and monstrous births: notes towards an appreciation of ideational drawing' in S.Garner (ed.), Writing on Drawing: Essays on Drawing Practice and Research. Bristol and Chicago, IL: Intellect.

Sale, Teel and Betti, Claudia (2011) Drawing: A Contemporary Approach. Wadsworth Publishing Co Inc; 7th edition.

Sapochnik, Carlos (2013) 'Drawing below the surface - eliciting tacit knowledge in social science research' in Drawing Knowledge, special edition of TRACEY, August 2013. Accessed online: www.lboro.ac.uk/departments/sota/tracey/.

Scott, Curie (2018) Elucidating Perceptions of Ageing Through Participatory Drawing: A Phenomenographic Approach. Unpublished PhD thesis, University of Brighton.

Simmons, S. (2011) Philosophical Dimensions of Drawing Instruction. In: A. Kantrowitz, A. Brew, and M. Fava (eds.), Thinking Through Drawing: practice into knowledge. New York: Columbia University, pp. 39-44. Online: http://ttd2011. pressible.org/files/2012/05/ Sontag, Susan (2003) Regarding the Pain of Others. New York: Farrar, Straus and Giroux. Taylor, Anita (2008) Foreword in S. Garner Writing on Drawing: Essays on Drawing Practice and Research. Bristol and Chicago, IL: Intellect.

Theron, Linda, Mitchell, Claudia, Smith, Ann and Stuart, Jean (eds) (2011) Picturing Research: Drawing as Visual Methodology. Rotterdam, Boston and Taipei: Sense Publishers. TRACEY Drawing and Visualisation Research Journal. Accessed online: www.lboro.ac.uk/departments/sota/tracey/.

Varela, F. J, Thompson, E. and Rosch, E. (1991) The Embodied Mind: Cognitive Science and human experience. Cambridge, MA and London: MIT Press.

Watts, Linda (2009) 'Managing self in role: Using multiple methodologies to explore self 
construction and governance' in S. Clark and P. Hoggett (eds.), Researching Beneath the

Surface. Psychosocial Research Methods in Practice. London: Karnac Books, pp. 215-239.

Weber, Sandra (2008) 'Visual images in research' in J. G. Knowles and A. L. Cole,

Handbook of the Arts in Qualitative Research: Perspectives, Methodologies, Examples and Issues. London: Sage. pp. 41-54. 